\title{
Novel soft members in double-layer space trusses
}

\author{
Yazmin Sahol Hamid ${ }^{1, *}$, Gerry Parke $^{2}$, and Nur Farzana Mohd Mahdi ${ }^{1}$ \\ ${ }^{1}$ Universiti Teknologi MARA Shah Alam, Faculty of Civil Engineering, Malaysia \\ ${ }^{2}$ University of Surrey, Department of Civil and Environmental Engineering, United Kingdom
}

\begin{abstract}
Progressive collapse of space structures has received much attention in recent years due to the recent failure of a double-layer space truss (DLST) stadium in Terengganu, Malaysia which collapse twice in Year 2009 and 2013. There is a considerable interest in understanding the collapse behaviour of space structures and possibility of improving its collapse behaviour. This phenomenon was demonstrated by earlier researchers, such as Collins (1981) and Parke (1988) which investigated the collapse behaviour both theoretically and experimentally. In their study a carefully designed DLST structure may possess reserve of strength in excess of their elastic capacity. Although DLST have a high degree of statically degree of statically indeterminacy, not all of them are robust, as it has been found a loss of one critical member could trigger the collapse of the entire structure. Usually the collapse of the DLST is influenced by the ductility behaviour of the compression members. The aim of this study was to investigate the use of novel soft member to reduce the catastrophic progressive collapse behaviour of DLSTs. A novel soft member was constructed to measure its behaviour under tensile and compressive loads. The term novel soft member used in this study is referred to a combination of three circular tubes which is made into one component and is used to support compressive load. It was found that using a blend of three circular tubes significantly increase the ductility behaviour of the member. These test illustrates that while the inner and outer tube experience compressive forces, the middle tube will continue to increase linearly. This indicates that there is a possibility of improving the collapse behaviour of DLST by incorporating the novel soft member.
\end{abstract}

\section{Introduction}

Progressive collapse analysis has been extensively studied and is attracting widespread interest for engineers and researchers all over the world. The termology of progressive collapse is defined as 'the spread of an initial local failure from element to element eventually resulting in the collapse of an entire structure or a disproportionately large part of it [1]. According to [2] a progressive collapse is a particular type of collapse which developes in a progressive manner akin to the collapse of a row of dominos. The triggering event to the study of progressive collapse is the collapse of Hartford Civic Center Coliseum Roof that occurred in 1978. From then on, the study of collapse has become salient in the field of engineering. Past tragic incidents of the collapse of space structures, have given very valuable lessons to designers. By understanding what had caused such failures, this may avoid any reoccurrence and help to develop safer alternatives.

\subsection{Collapse behaviour of compression member}

A DLST is a common structure used in building stadiums, factories, warehouses, airports in which all these structures are column free area. In brief, DLSTs

\footnotetext{
* Corresponding author: minbelle@yahoo.com
}

are used for large span structures with few or even without intermediate supports. One of the advantages is because a double -layer grids is usually highly indeterminate where the forces are distributed widely to all members, causing each member to acquire a relatively low value of internal force [3]. Compression is a major discussion suggested under DLST in which if a structure is loaded beyond the elasticity of the members, it would then lead to collapse [4]. For a collapse to take place, the strength or load carrying capacity of a DLST is normally assessed by considering the elastic load displacement response of the structure up to the point where the first compression member fails. The inelastic behaviour of the structure is usually ignored in the design process because it is considered that due their high degree of static indeterminacy, double-layer space truss fabricated from ductile materials will possess reserve of strength in excess of their elastic capacity. However, this has shown otherwise. This is strongly proven when the force distribution resulting from the failed members can lead to failure of other members [5]. It can be summarised that the elastic and plastic buckling of a compression member is a dynamic process resulting in a sudden loss of both member stability and load carrying capacity. 


\subsection{Novel soft member}

Due to the recent failures of progressive collapse in DLST structures, several researchers are working on ways to improve the performance of the space truss behaviour by achieving a much smoother and ductile response of the structure. The results by [6] show that the method of strengthening the compression layer members along with weakening the tension layer members is an effective method for retrofitting the DLST behaviour against progressive collapse. [7] highlighted that material and geometric nonlinearities are important factors to be considered in the collapse behaviour of space truss structures. [8] researched on buckling restrained brace comprising of three circular tubes in which the slotted holes are arranged in the middle tube, which exhibits excellent performance in its deformation capacity and low cyclic fatigue behaviour.

Another dimension to be discussed is the novel soft member of DLST. [5] participated in experimental work involving investigation for the possibility of improving DLST structures. In order to capture both the loaddisplacement response and the collapse behaviour he tested four specimens and loaded them up to collapse under displacement controlled hydraulic actuator. Two of his experiments incorporated a novel force limiting device to improve the behaviour of his first two specimens. A novel soft compression member is a member designed to overcome the lack of control in load -displacement response in a DLST structure. It acts as a 'soft member' which reduced the axial stiffness and acts as a load limiting device. The steel constructed institute cited by [5] proposed by Constrado came up with the concept of the soft member. In this study, these initial concepts have been investigated and broadens the application of novel soft compression members. The highly stressed compression members in DLST are susceptible to sudden collapse but with the inclusion of novel soft members the collapse failure could be minimized. Novel soft member is combining three different diameters that consist of an outer, middle and inner tube to form one specimen. However, although the effect of the novel soft member on the load and displacement response was demonstrated decades ago, the full size soft members that was designed and tested by [5] do not work when there is bending in the member because the tubes lock up.

This paper presents a series of compression test to examine the relationships between load and displacement of space truss member with and without incorporating novel soft members. The primary aim in this study is to re look at the concept of development of novel soft compression members formed using a new design to refine the members' load-displacement response.

To date most studying have problems arising from the use of force limiting devices that are lacking in control of their load-displacement characteristics. Among the problems faced are large fluctuations in their working load limits, high initial load occurring before the load increased and stabilized at the working load limit. In this study the researcher will try to overcome these problems by designing a novel soft member type with reduced axial stiffness and as a load limiting device. The role of the novel soft member or concept is extended to incorporate this load -limiting potential device for the improvement of force distribution within the members in a double-layer space truss. In conclusion a large part of this research will be devoted to designing, testing and improving the novel soft limiting device. If critical members in a space structures is incorporated with these novel soft member perhaps a much more ductile or smooth load displacement behaviour could be achieved plus preventing from a sudden catastrophic collapse behaviour to occur.

\subsection{Methodology}

The load-displacement behaviour of individual space truss members has great importance in the collapse behaviour of space truss structures. It is therefore essential to know that the material is rigid and strong enough to withstand or cater the loads in a ductile behaviour. One attempt to improve our understanding of collapse behaviour is the study of the mechanical properties of the novel soft member proposed under tensile and compression test. In [5] it was shown that carefully designed double-layer structures may possess reserves of strength in excess of their elastic capacity. Here we demonstrate that buckling of a novel soft member under concentrated load may not lead to the collapse of the entire structure, thus will give greater warning before failure and their application may be applied in design and construction on DLSTs. Therefore, before the novel soft member with three steel tubes can be practically used in critical members of the space truss system, their behaviour under tensile and compressive loads need to be investigated.

\subsection{Experimental study}

\subsubsection{Details of the novel soft member}

In this study, circular hollow steel products of carbon steel of seamless tubes were used accordance with Eurocode EN 10204 3.1. Six-metre-long steel tube produced by manufacturer, was cut into $1 \mathrm{~m}$ length for each size. These steel tube were supplied by Soon Hoe Steel Sdn. Bhd., Section 36, Shah Alam, Selangor, Malaysia. There are three different size of outer, middle and inner tube which is labelled as T1, T2 and T3. Outside diameter for T1, T2 and T3 are $48.6 \mathrm{~mm}, 60.8$ $\mathrm{mm}$ and $73.0 \mathrm{~mm}$ respectively. Then, to form space truss member incorporating novel soft member T1, T2 and T3 is connected by welded at perimeter area. Member types classified in Table 1 as T1, T2 and T3 have been used in the fabrication of the novel soft members. Whereas for space truss member without incorporating novel soft member only consist of inner tube, labelled as T1 with outside diameter $48.6 \mathrm{~mm}$. Plan view of space truss 
member incorporating novel soft members and crosssection A-A are shown in Figure 1.

Table 1. Member type with section sizes.

\begin{tabular}{|c|c|c|c|}
\hline $\begin{array}{l}\text { Member } \\
\text { labelled }\end{array}$ & $\begin{array}{c}\text { Outisde } \\
\text { Diameter } \\
(\mathrm{mm}) \\
\end{array}$ & $\begin{array}{c}\text { Wall } \\
\text { Thickness } \\
(\mathrm{mm}) \\
\end{array}$ & $\begin{array}{c}\text { Cross } \\
\text { Sectional } \\
\text { Area }\left(\mathrm{mm}^{2}\right) \\
\end{array}$ \\
\hline $\mathrm{T} 1$ & 48.6 & 3.8 & 535 \\
\hline $\mathrm{T} 2$ & 60.8 & 4.4 & 780 \\
\hline T3 & 73 & 5.0 & 1068 \\
\hline
\end{tabular}

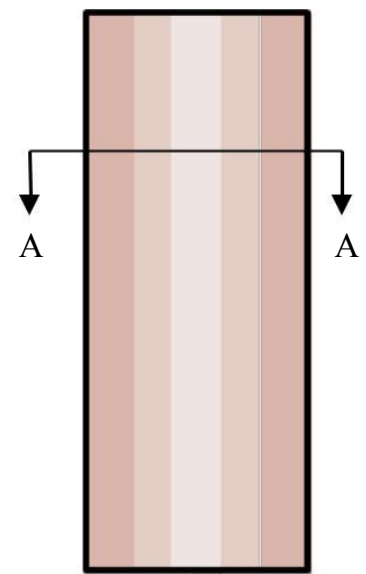

(i)

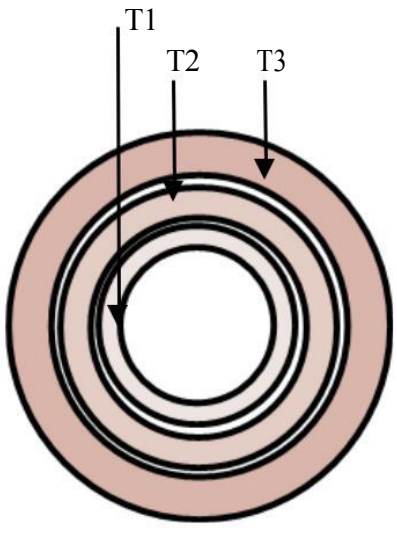

(ii)
Fig. 1. Elevation (i) and plan view of space truss member incorporating novel soft members and Cross-section A-A.

\subsubsection{Ductility behaviour}

The ductility of steel is one of the parameters that influence the behaviour of the space truss system. By increasing the ductility of the space truss members, it can reduce the progressive collapse of the structure. For example, when steel demonstrates a high ductility behaviour, warning to occupants can be achieved before a complete collapse of a structure is imminent. When three circular tubes subjected to axial compression loads, while the inner and outer tube is subjected to compressive stress the middle tube experience tensile stress. Provided that the compression force in the inner and outer tubes is always insufficient to cause premature elastic buckling of both of these members, the tensile force in the middle tube will continue to increase linearly. Additionally, yielding of a tension member has more redundancy since distribution of load can occur in several ways, while buckling of a compression member is far more catastrophic. This shows that the combination of three types of steel in the truss members helps each other to make sure the structure is very ductile.
In the case of the middle tube member, the tensile test is performed to measure the amount of elongation of a member to breaking point by applied force. On the basis of these criteria, it then describes the preparation of a set of tubes members which must have a measurable yield strength at which unrecoverable plastic deformations begins. This condition must also satisfy a condition i.e. to reach rupture strain of at least $20 \%$. Tensile test was carried out for diameter of inner tube (T1) member, diameter of middle tube (T2) member and diameter of outer tube (T3) member using a Universal Testing Machine, UTM -1000 (1000 kN capacity) to study the deformation characteristics of the tube members forming the novel soft member. The specimens studied has been cut into a dog bone shape where it will react to load being applied in tension known as pulling action. The design of specimen is in accordance with British Standard, BS 18: 1987: Tensile Testing of Metals and ISO 6892: Metallic Material Tensile Testing (1984). Typical details of the tensile specimen, is illustrated in Figure 2. The specimen tested has a shoulder at each end and gage section in between i.e. $70 \mathrm{~mm}$ and $110 \mathrm{~mm}$ respectively. In order to make sure the tensile machine can achieve its full capacity a firm grip sample is important during testing. Since the samples have a nonstandard shape, therefore, with an aid of a hammer only the shoulders of each end of the specimens were flattened to facilitate the holding of the test samples. Speed rate that was used is $2 \mathrm{~mm} / \mathrm{min}$.

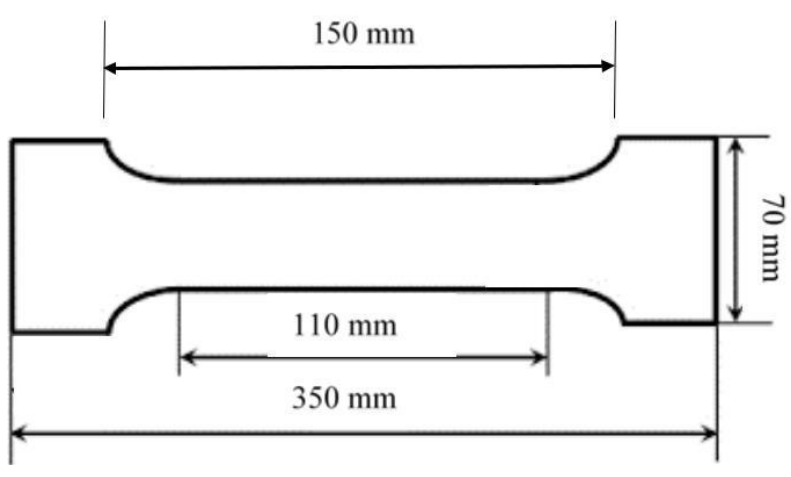

Fig. 2. Dimension of tensile specimen

\subsubsection{Connection detail}

The influence of structural joint connections between structural elements greatly influence the stiffness of the structure model. In this study, connections between the novel soft members are welded to create fusion between the three tube members. The middle tube is connected in between the outer and inner tube near both ends by welding, with the intention of sustaining their proper relative position. Figure 3 (i) and (ii) shows the elevation 
view of the inner, middle and outer tube of the members with (S1) and without (S2) incorporating novel soft members that has been fabricated respectively. The inner tube was welded to the middle tube at the perimeter while the middle tube was welded to outer tube at loactions illustrated in Figure 4.

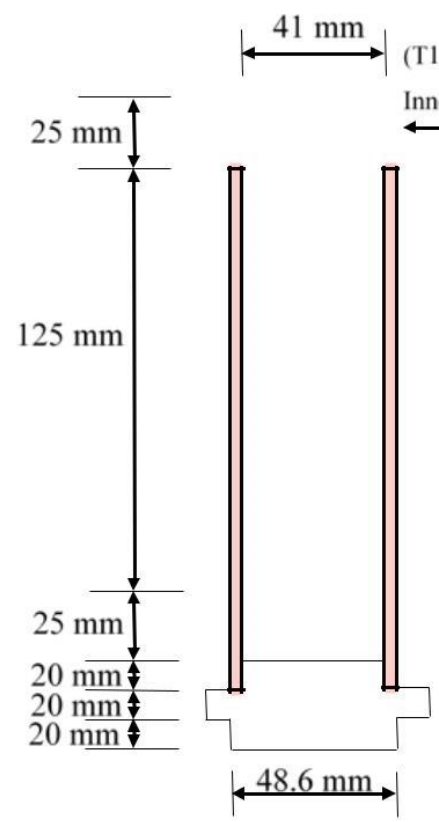

(i)

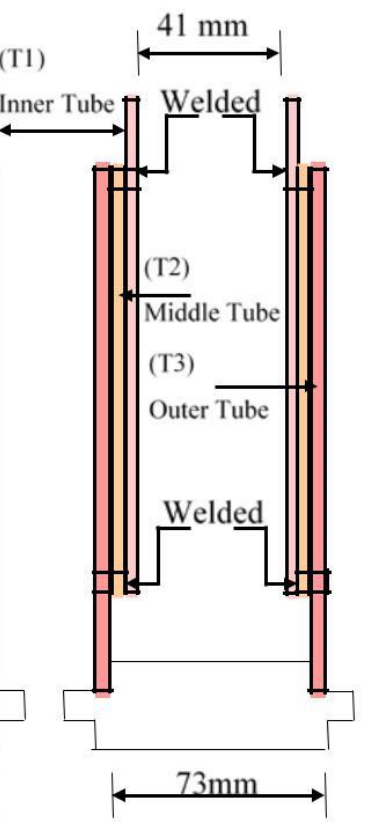

(ii)
Fig. 3. Elevation view of (i) S1 and (ii) S2.

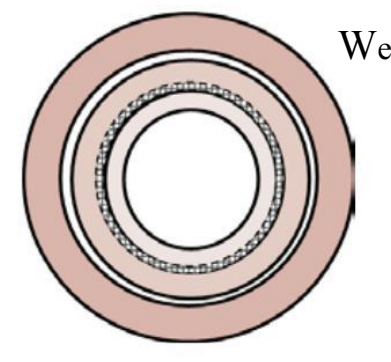

(i) Top view

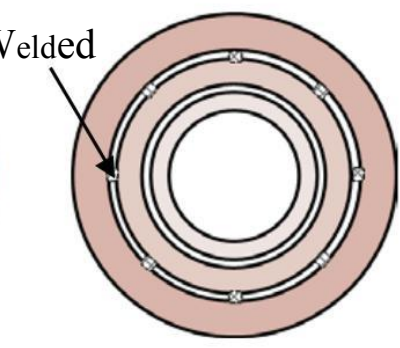

(ii) Bottom view
Fig. 4. Plan view of S2.

\subsubsection{Compression Test}

In this study, a small novel soft member prototype model was tested experimentally using a compression testing machine available at Heavy Structure Laboratory, Faculty of Civil Engineering, UiTM Shah Alam. The specimen is compressed using a Universal Testing Machine (UTM) of $2700 \mathrm{kN}$ capacity. Fig. 5 shows the experimental set up of the compression test machine. The circular hollow section tubes were $175 \mathrm{~mm}$ in length for each S1 and S2 member members. The instrumentation of the test consists of loading mechanism, hydraulic test pump, control unit, strain gauge and displacement transducer. The loading mechanism is measured by an electronic load cell incorporated in the hydraulic actuator. Strain gauges were pasted at top and bottom between mid -height of the specimen in vertical direction to record the strain values. One vertical displacement transducer was placed at the edge of the upper plate to measure the vertical deflection. The test sample is placed in between two plates that distribute the applied loads. The goal of this test is to determine the behaviour or response of the material incorporating novel soft members whereby the fundamental variables such as strain, stress and deformation is recorded. The displacement rate that was used during testing was $0.02 \mathrm{~mm} / \mathrm{sec}$. A total of three novel soft members with the same configurations were tested for compression test mentioned earlier. This method obtains compressive strength, yield strength, ultimate strength, elastic limit and the elastic modulus values. The importance of these parameters concludes whether or not the specimen suggested in this study is suited for the specific application. The application context in this study refers to the space truss structure whereby a ductile load-displacement response is preferred rather than a brittle fracture behaviour.

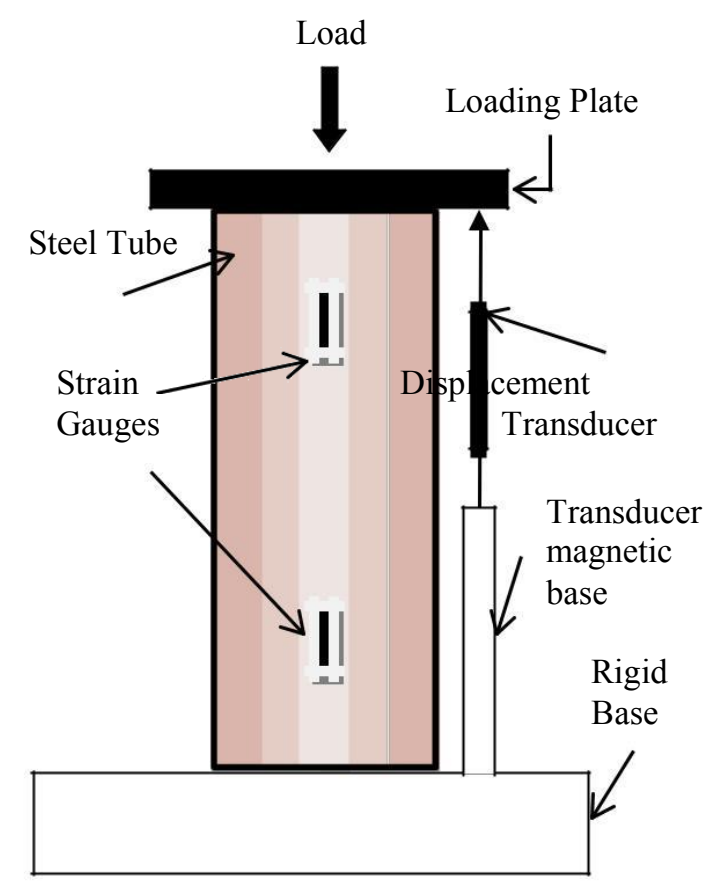

Fig. 5. Components of Compression Test Machine

\section{Results}

\subsection{Tensile Test Results}

Several members (Table 1) including ordinary tube members and novel soft members (Figure 3 (ii)) will be tested to determine their physical properties and the loaddisplacement behavior of the individual tension (Figure 6) and compression members (Figure 8). In this study 
the middle tube has to plastically deform $25 \mathrm{~mm}$ for the whole assemble to work properly. If the tube can stretch $30 \%$ then the results expected can't be achieved, if not then the section size may have to be reduced down to $25 \mathrm{~mm}$ or $20 \mathrm{~mm}$. A minimum of three T2 tube specimens labelled TS2.1, TS2.2 and TS3 was tested under tensile test. Fig 6 shows the stress-strain relationship obtained from tensile testing, yield strength for TS2.1 is 323.94 $\mathrm{MPa}, \mathrm{TS} 2.2$ is $313.66 \mathrm{MPa}$ and TS2.3 is $330.23 \mathrm{MPa}$. According to EN 1992-1-1 is valid for yield stress of steel in the range $400-600 \mathrm{MPa}$. From the graph, it shows TS2.2 reach stress level first which plastic deformation initiates compared to TS2.1 and TS2.3. All TS2 specimens approached that standard limit. Next, ultimate strength for TS2.1 is $470.61 \mathrm{MPa}, \mathrm{TS} 2.2$ is $446.46 \mathrm{MPa}$ and TS2.3 is $464.20 \mathrm{MPa}$. So, TS2.1 have higher ultimate strength compared to others as the load increases to nearly maximum and the specimen started to fail. Based on ASTM A36 Steel Standard, ultimate tensile strength is between $400-550 \mathrm{MPa}$ which all the specimens TS2 were between the limit and shows ductile behaviour. From the graph, TS2.3 shows it received high load to achieved yield strength. This means TS2.3 have high elastic region compared to others. However, TS2.1 shows more high in strength compare to others and have more ductility behaviour which is deforms more plastically before fracture. Elastic Modulus for TS2.1 is $19 \mathrm{~N} / \mathrm{mm}^{2}$, TS2.2 is $16 \mathrm{~N} / \mathrm{mm}^{2}$ and TS2.3 is $21 \mathrm{~N} / \mathrm{mm}^{2}$. It is proven that TS2.1 could cater high load longer and not suddenly fails.

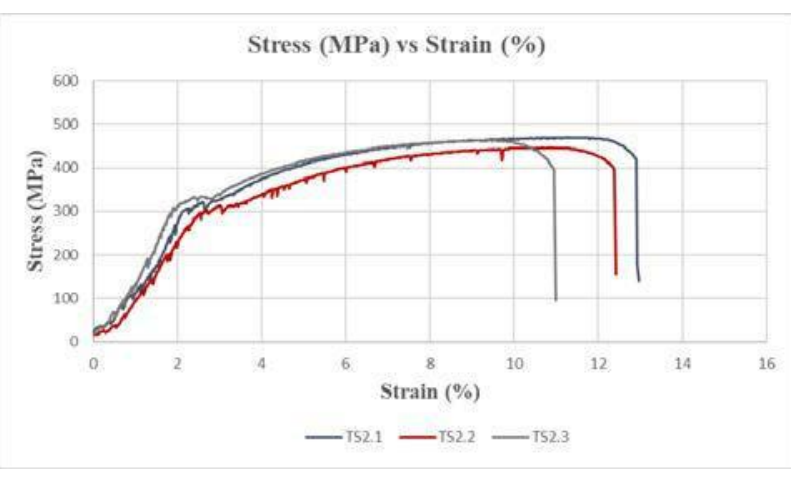

Fig. 6. Stress-strain graph for T2

The grade of steel denotes the specified characteristics yield stress. It is obtained by dividing the characteristic yield load by the nominal cross-sectional area of the steel. $0.2 \%$ proof stress is substituted as the yield stress. Typical and idealized stress-strain diagrams accordance to EN 1992-1-1 is valid for yield stress of steel in the range $400-600 \mathrm{~N} / \mathrm{mm}^{2}$. The characteristic design strength of the more common types of steel currently used in the UK was given in BS4449 (2005) is $500 \mathrm{~N} / \mathrm{mm} 2$ that normally denotes as Grade 500 and has been adopted by the UK reinforcement industry [9]. So, the three different circular hollow steel section TS1, TS2 and TS3 were approach within the specified limit and show ductile behaviour in plotted graph. Ductility is inversely related to yield stress. Therefore, in application where ductility is critical, it is important to ensure that the actual yield strength does not exceed the specified value.

The ductility of a material is a measure of the extent to which a material will deform before fracture. Percentage elongation was determined to measure ductility of steel behaviour. High values of percentage elongation indicate that material is very ductile. Low values indicate that material is brittle and has low ductility. For mild steel, the percentage elongation usually is $20 \%$ or more (Gupta, 2009). According to Design of Steel Structures, EN 1993(EC3), elongation at failure is not less than $10 \%$. From the testing result, average for percentage elongation break for TS1 is $14.44 \%$, TS2 is $14.01 \%$ and TS3 is $14.67 \%$.

Next, ductile behaviour also can be determined by percentage reduction of area. Reduction of area is the proportional reduction of the cross-sectional area of a tensile test specimen at the plane of fracture measured after fracture. Average percentage reduction of area for TS1 is $27.9 \%$, TS2 is $21.74 \%$ and TS3 is $28 \%$ which TS3 have higher percentage reduction of area due to high thickness compared to TS1 and TS2.

The circular steel section experienced ductile behaviour while undergo tensile test. It is shows high in ultimate tensile strength which maximum strength that steel could withstand with high percentage elongation and reduction in area of the specimen. Figure 7 shows the specimen after testing for specimen TS2. The pictures show the location the failure or necking occur.

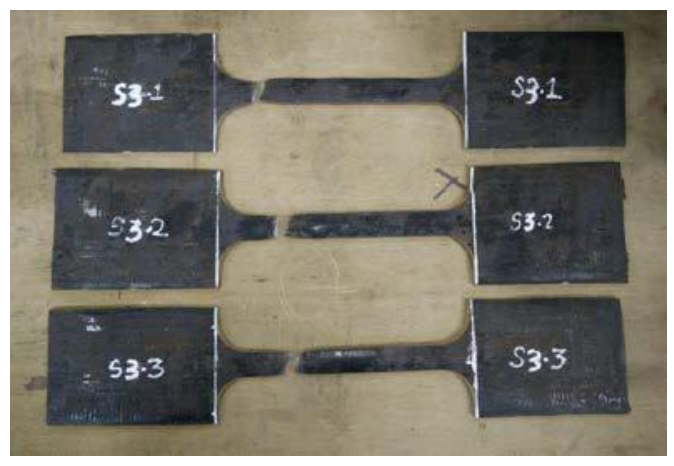

Fig. 7. Specimen T2 after testing.

\subsection{Compression Test Results}

The compressive strength gives the ratio of the maximum applied force by cross-sectional area to compressed the specimen. Three samples from each type of specimen configuration i.e. specimen S1 and S2 was tested and recorded for its compressive strength value. The first two letters refer to the type of specimen tested while the values in the bracket refers to numbers of specimen tested with the same configuration." Table 2 shows summary of compressive strength while Fig. 8 shows the picture of the specimens after testing for specimen $\mathrm{S} 1$ and $\mathrm{S} 2$ respectively. After steel reaches its yield strain, an outward indent or bulge formed adjacent at the bottom to the specimens under compression test was observed in specimen S1. Whereas for specimen S2 the bulged is formed on upper and lower face of the 
specimen when load was applied. The bulged then grew with load cycling and increasing vertical deformation until the bulged formed side by side on specimen.

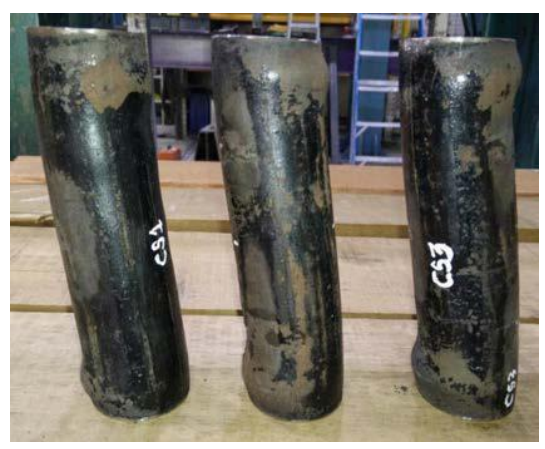

(i) Specimen S1 after testing

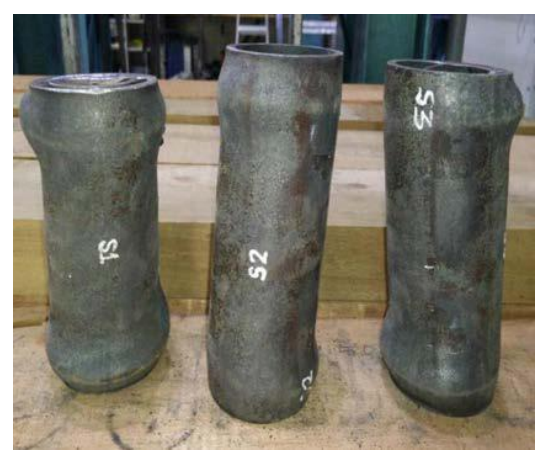

(i) Specimen S2 after testing

Fig. 8. (i) Specimen $\mathrm{S} 1$ and (ii) S2 after testing

Table 2. Summary of Compressive Strength of S1 and S2

\begin{tabular}{|c|c|c|c|c|c|c|}
\hline \multirow{2}{*}{ Specimen } & \multicolumn{3}{|c|}{ S1 } & \multicolumn{3}{|c|}{ S2 } \\
\cline { 2 - 7 } & S1(1) & S1(2) & S1(3) & S2(1) & S2(2) & S2(3) \\
\hline $\begin{array}{c}\text { Maximum } \\
\text { Load } \\
\left(\times \mathbf{1 0}^{3}\right)(\mathbf{N})\end{array}$ & 272 & 270 & 257 & 587 & 487 & 484 \\
\hline Area (mm $\left.{ }^{\mathbf{2}}\right)$ & \multicolumn{3}{|c|}{535} & \multicolumn{3}{|c|}{535} \\
\hline $\begin{array}{c}\text { Compressive } \\
\begin{array}{c}\text { Strength } \\
\left(\mathbf{N} / \mathbf{m m}^{2}\right)\end{array}\end{array}$ & 509 & 505 & 481 & 1097 & 912 & 905 \\
\hline
\end{tabular}

The highest compressive strength for specimen S1 was $509.33 \mathrm{~N} / \mathrm{mm}^{2}$ and $\mathrm{S} 2$ was $1097.74 \mathrm{~N} / \mathrm{mm}^{2}$ respectively. This shows that $\mathrm{S} 2$ is more ductile compared to $\mathrm{S} 1$ because of the novel soft member. Table 3 shows summary of the compressive test results.
Table 3. Summary of test results for compressive test

\begin{tabular}{|c|c|c|c|c|c|c|}
\hline \multirow{2}{*}{ Specimen } & \multicolumn{3}{|c|}{ S1 } & \multicolumn{3}{c|}{ S2 } \\
\cline { 2 - 7 } & S1(1) & S1(2) & S1(3) & S2(1) & S2(2) & S2(3) \\
\hline $\begin{array}{c}\text { Load at first } \\
\text { deform (kN) }\end{array}$ & 201 & 200 & 207 & 343 & 351 & 339 \\
\hline $\begin{array}{c}\text { Displacement at } \\
\text { first deform } \\
\text { (mm) }\end{array}$ & 2.84 & 1.83 & 1.98 & 2.16 & 3.02 & 2.13 \\
\hline $\begin{array}{c}\text { Load at yield } \\
\text { point (kN) }\end{array}$ & 211 & 210 & 215 & 360 & 367 & 358 \\
\hline $\begin{array}{c}\text { Displacement at } \\
\text { yield point } \\
\text { (mm) }\end{array}$ & 3.45 & 2.30 & 2.33 & 2.70 & 3.60 & 2.7 \\
\hline $\begin{array}{c}\text { Load at } \\
\text { ultimate point } \\
\text { (kN) }\end{array}$ & 272 & 270 & 257 & 587 & 487 & 484 \\
\hline $\begin{array}{c}\text { Displacement at } \\
\text { ultimate point } \\
\text { (mm) }\end{array}$ & 9.57 & 8.16 & 6.58 & 19.92 & 11.65 & 17.77 \\
\hline
\end{tabular}

Based on Figure 9, it can be observed that the S2 could sustain the highest maximum load which is approximately about $500 \mathrm{kN}$ to $600 \mathrm{kN}$ and the strength increase by $50 \%$ compared to $\mathrm{S} 1$ which could resist load below than $300 \mathrm{kN}$. S2 also experienced maximum deflections and have more ductile behaviour compared to $\mathrm{S} 1$. Therefore, S2 could sustain higher load in long duration whereby it has achieved the performance required such the members have enough strength to carry load to be able to sustain permanent deformation.

Therefore, specimen S2 may be applied on critical members in a DLST structure which incorporate novel soft member perhaps as a much more ductile or smooth load displacement behaviour could be achieved plus preventing from a sudden catastrophic collapse behaviour to occur. Therefore, by incorporating these novel soft member, the collapse behaviour of a DLST structures can be improved whereby it will give warning rather than catastrophic behaviour.

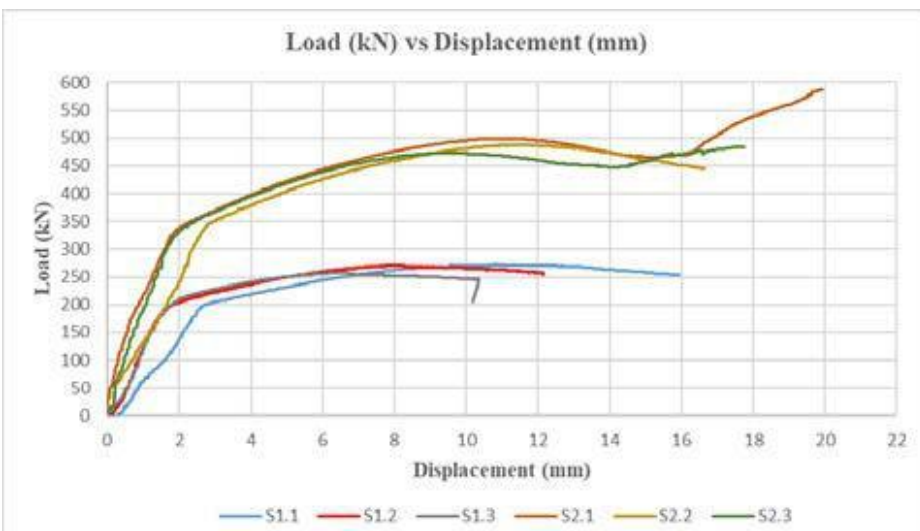

Fig. 9. Graph load vs displacement of specimen S1 (S1(1), S1(2) and S(3) and specimen S2 (S2(1), S2(2) and $\mathrm{S} 2(3))$. 


\section{Conclusion}

Therefore, by incorporating these novel soft member, the collapse behaviour of space structures can be improved whereby it will give warning rather than suddenly collapse. This study broadens the application of novel soft compression members and enables the assessment of risk of vulnerable members to ease engineers in identifying critical members to cause progressive collapse. In conclusion this study also helps to promote research strengthening techniques particularly to increase construction development in our country. Besides this research will help the government to ensure the constructability and feasibility of structures constructed are reliable and also economic. This novel soft member is proven to provide help to industries in dealing with new challenges in the future, alternative solutions to mitigate progressive collapse and provide guidance to practicing engineers.

\section{Recommendations}

Further investigation is suggested to attach a shorter version of the soft member, i.e. approximately about 200 $\mathrm{mm}$ long on top of a tubular member to change its stiffness value. This is done by designing and testing the shorter members and then reattach them to a normal member and then test the full assembly. Presently, this analysis only considers experimental work, analysis of these model in ABAQUS would be useful to compare their behaviour with experimental work.

The Authors would like to thank Ministry of Higher Education Malaysia (MOE), and Universiti Teknologi Mara (UiTM) Shah Alam for providing financial support through Lestari Grant (File no: 600-IRMI/MyRA 5/3/LESTARI (0148/2016), and acknowledge the University of Surrey for their Academician expertise.

\section{References}

1. American Society of Civil Engineers, Minimum design loads for buildings and other structures (American Society of Civil Engineers, 2013)

2. The Institution of Structural Engineers, Manual for the systematic risk assessment of high-risk structures against disproportionate collapse (The Institution of Structural Engineers, 2013)

3. Liu, J.L., Preventing progressive collapse through strengthening beam-to-column connection, Part 1: Theoretical analysis (Journal of Constructional Steel Research, 2010)
4. Mwakali, J.A., Collapse studies of the $s$ of eccentricity in compression Tee-section chords in double-layer space trusses (Fourth International Conference on Space Structures, University of Surrey, Guildford, Thomas Telford Services Ltd. pp. 16-27, 1993)

5. Parke, G.A.R., The Behaviour of Space Trusses Incorporating Novel Compression Members (University of Surrey, United Kingdom, 1988)

6. Rashidyan, S. \& Sheidaii, M., Improving doublelayer space trusses collapse behavior by strengthening compression layer and weakening tension layer members (Advances in Structural Engineering, 2017)

7. Blandford, G.E., Progressive Failure Analysis of Inelastic Space Truss Structures (Computers \& Structures, 1996)

8. Zhang Dongbin, Nie Xin, Pan Peng, Wang Mengzi, Deng Kailai, Chen Yabin, Experimental study and finite analysis of a buckling-restrained brace consisting of three steel tubes with slotted holes in the middle tube (Journal of Construction Steel Research. 2016)

9. Beeby. A. W and Narayanan. R. S., Designers' Guide to EN 1992-1-1 and EN 1992-1-2 (Eurocode 2: Design of Concrete Structures: General Rules and Rules for Buildings and Structural Fire Design, 1992) 